\title{
Pancreatic theory of relativity...
}

\author{
S. Hać \\ Department of General Endocrine and Transplant Surgery, Medical University of Gdansk, Poland
}

[Received: 8 July 2018; Accepted: 2 September 2018]

\begin{abstract}
Pancreatic duct and parenchyma has different benchmarks in nomenclature. The author discusses the proposition to unify the description system of procedures and surgeries within pancreas according to the direction of pancreatic juice natural flow. (Folia Morphol 2019; 78, 2: 431-432)
\end{abstract}

Key words: pancreas

Pancreas is the organ of digestive tract playing an important role in fat and protein digestion and glucose metabolism. The gland is composed of two embryo buds. Pancreas is conventionally divided, from the anatomical point of view, into the head, isthmus, corpus and tail, with no strict border between these parts. The pancreas has the typical configuration; glandular cells form glands with single small duct joining together to form larger one and all are drained into main pancreatic duct going along the whole pancreas. Within the head of the pancreas, two ducts exist as a consequence of embryo development. Two ducts have usually separate connections with the duodenum.

The lexical definitions of proximal and distal terms are descriptive and may have different meanings. According to Oxford Medical Dictionary [7], 'proximal' means situated close to the origin or point of attachment or close to the median line of the body. 'Distal' is situated away from the origin or point of attachment or from the median line of the body. The term is applied to a part of the limb that is furthest from the body; to a blood vessel that is far from the heart; and to a nerve fibre that is far from the central nervous system.

Proximal and distal - are universally used terms describing the position or relation within human body. There are two main benchmarks; central part of the body and direction of flow (blood or other fluids). The first one is used to express the positioning on extremities. The second one is used to describe the circulatory and digestive system relations. An example might be: "artery stenosis with proximal thrombus formation" or "bowel obstruction with proximal distension". The matter is not so clear concerning the pancreatic gland and pancreatic duct. The gland has typical excretory duct. The description of pancreatic duct occlusion with proximal distension means that the part of pancreas between occlusion and tail is involved. "Dilatation of the pancreatic duct proximal to the tumour..." means left to the tumour or "The abdominal computed tomography scan revealed dilation of the proximal pancreatic duct with an irregular high density calcification shadow located at the head of the pancreas" [5]. On the other hand, the resection of pancreas is sometimes called "distal pancreatic resection", which means that left part of the gland is removed [1,9]. Another description of pancreatic relations is the following example: "A 3-cm hypovascular mass accompanying a large distal pseudocyst in the pancreatic tail" by Hamada et al. [3]. In that paper, the authors refer to the same situation as described by Liu et al. [5]. The part of pancreatic duct after head resection is called distal pancreatic duct. The resection of pancreatic head is sometime called proximal pancreatic resection, like in the paper by Lu et al. [6]: "For tumours in the head and uncinate process, the surgeon would palpate the tumour with Kocher's manoeuvre to evaluate the risk and possibility of EU, followed by careful dissection of proximal pancreas". Some authors call Santorini duct

Address for correspondence: S. Hać, MD, PhD, Department of General Endocrine and Transplant Surgery, Medical University of Gdansk, ul. Dębinki 7, 80-952 Gdańsk, Poland, e-email: sthac@gumed.edu.pl 
as regressed proximal main duct of dorsal pancreatic bud [4]. Recent review papers of pancreatic anatomy also give unclear description: "The ventral pancreatic duct and the distal part of the dorsal pancreatic duct are anastomosed and form the MPD of Wirsung, while the proximal part of the dorsal pancreatic duct becomes the APD of Santorini" [2]. This few examples show dual benchmark related to pancreatic gland. One approach takes into account the pancreatic juice flow, while the other one - the position in relation to the central axis of the body. Usually the pancreatic juice flow direction is refered by the endoscopists, relation to the duodenum is used by surgeons. However the surgical drainage procedures are performed proximally to the obstruction [8].

The problem is not only restricted to nomenclature but it may also affect clinical practice. On the other hand the sentence "Distal pancreatic resection was performed, proximal to obstruction site" or "Pancreatic head resection was performed and distal part of the gland was anastomosed with jejunal loop" sounds strange. It might be confusing and leads to misunderstanding.

In my opinion it is reasonable to recommend that the term 'proximal pancreas' refers to the left part of the organ, and the term 'distal pancreas' - to its head, according to the pancreatic juice natural flow direction.

\section{REFERENCES}

1. Alexakis N, Halloran C, Raraty M, et al. Current standards of surgery for pancreatic cancer. Br J Surg. 2004;
91(11): 1410-1427, doi: 10.1002/bjs.4794, indexed in Pubmed: 15499648.

2. Dimitriou I, Katsourakis A, Nikolaidou E, et al. The main anatomical variations of the pancreatic duct system: review of the literature and its importance in surgical practice. J Clin Med Res. 2018; 10(5): 370-375, doi: 10.14740/ jocmr3344w, indexed in Pubmed: 29581798.

3. Hamada T, Nanashima A, Hiyoshi M, et al. Curative distal pancreatectomy in patients with acinar cell carcinoma of pancreas diagnosed by endoscopic aspiration via esophago-jejunostomy: A successful case report. Int J Surg Case Rep. 2018; 42: 274-279, doi: 10.1016/j.jiscr.2017.12.040, indexed in Pubmed: 29331883.

4. Kamisawa T, Takuma K, Tabata T, et al. Clinical implications of accessory pancreatic duct. World J Gastroenterol. 2010; 16(36): 4499-4503, indexed in Pubmed: 20857518.

5. Liu $Q$, Wang $Y$, Zeng $H$, et al. Successful endoscopic removal of a rare, large impacted pancreatic duct stone using grasping forceps: A case report with video. Medicine (Baltimore). 2018; 97(14): e0304, doi: 10.1097/ MD. 0000000000010304 , indexed in Pubmed: 29620654.

6. Lu WJ, Cai HL, Ye MD, et al. Enucleation of non-invasive tumors in the proximal pancreas: indications and outcomes compared with standard resections. J Zhejiang Univ Sci B. 2017; 18(10): 906-916, doi: 10.1631/jzus.B1600597, indexed in Pubmed: 28990381.

7. Martin EA. Oxford Concise Medical Dictionary. 7th edition. Oxford University Press, cop. Market House Books Ltd, Oxford New York 2004: 567.

8. Mihaljevic AL, Kleeff J, Friess H. Beger's operation and the Berne modification: origin and current results. J Hepatobiliary Pancreat Sci. 2010; 17(6): 735-744, doi: 10.1007/ s00534-009-0179-2, indexed in Pubmed: 19798464.

9. Toh BC, Rao J. Laparoscopic D2 total gastrectomy and enmass splenectomy and distal pancreatectomy for locally advanced proximal gastric cancer. Surg Endosc. 2018; 32(4): 2156, doi: 10.1007/s00464-017-5801-9, indexed in Pubmed: 28842726. 